\title{
Follow-up With Objective and Subjective Tests of the Sleep Characteristics of Patients After Cardiac Surgery
}

\author{
Hikmet Yilmaz, MD; Ihsan Iskesen, MD*
}

\begin{abstract}
Background The purpose of this study was to investigate the changes in sleep characteristics in patients who underwent coronary artery bypass grafting $(\mathrm{CABG})$ surgery, using both subjective and objective tests in the early (preoperative) and late (postoperative) periods.

Methods and Results Forty-five patients who underwent CABG and did not previously have any sleep disturbance were evaluated by subjective and objective sleep parameters during a consecutive 3-5-day preoperative examination, during a consecutive 5-8-day period in the $1^{\text {st }}$ postoperative week, and during consecutive 5-8-day periods in the $1^{\text {st }}$ and $2^{\text {nd }}$ postoperative months. The Pittsburgh Index and Epworth Sleepiness Scale values, sleep latency, napping episodes, total napping period, duration of wakefulness after sleep onset and fragmentation index values were significantly increased; however, Maintenance of Wakefulness Test lengths, total sleep time and sleep efficiency were significantly decreased in the $1^{\text {st }}$ postoperative week. All of these were the same in the $1^{\text {st }}$ postoperative month and differences were not statistically different from the preoperative period. None of the sleep parameters in the $2^{\text {nd }}$ postoperative month differed from the values obtained in the preoperative period.

Conclusion The cause of sleeplessness after CABG surgery may be temporary deterioration of circulation in the centers of the brain stem and hypothalamus that control sleep and awakening. Improvement of the circulation in these centers a few months after the operation helps to regain sleep control, and thus sleep disturbances disappear. (Circ J 2007; 71: 1506-1510)
\end{abstract}

Key Words: Bypass graft surgery; Sleep disturbance follow-up; Sleep parameters

$\mathbf{S}$ leeplessness, poor sleep quality, and lack of sleep continuity (difficulty falling asleep, restless sleep with frequent nocturnal awakenings, and early morning awakenings) are common among patients during recovery after coronary artery bypass grafting $(\mathrm{CABG})$ and may have important effects on morbidity, mortality, and quality of life $!^{-5}$ Numerous intrinsic (eg, age, gender, illness, primary sleep disorders) and extrinsic (eg, environment, medical treatment) factors are thought to influence sleep throughout the preoperative period, hospitalization, and recovery? Many studies describe that sleep is disturbed in the early period after CABG surgery, $1,5,6$ and the aim of the present study was to determine when these sleep disturbances improve. Alterations of sleep patterns, deprivation of total sleep time (TST), increments of slight sleepiness, suppressed rapid-eye movement sleep, increased daytime napping episodes and durations, and as a consequence of these factors, decreased sleep efficiency (SE) after CABG surgery have been reported in numerous studies!, $, 4,5-8$ Only telephone survey results, 3 , self-reported questionnaire forms, 2,9 subjective sleep tests or sleep $\operatorname{logs},, 8,10-12$ or objective parameters only ${ }^{13}$ have been evaluated, and furthermore follow-up periods were long in the studies using self reported questionnaire forms and subjective sleep tests, ${ }^{4,10,11,14}$ but were

(Received April 10, 2007; revised manuscript received June 11, 2007; accepted June 21, 2007)

Departments of Neurology, *Cardiovascular Surgery, Celal Bayar University School of Medicine, Manisa, Turkey

Mailing address: Ihsan Iskesen, Cardiovascular Surgery, Celal Bayar University, Celal Bayar Universitesi Tip Fakultesi Kalp Damar Cerrahisi, Manisa, 45030 Turkey very short in the studies that used objective sleep parameters ${ }^{13}$ None of these studies had control groups of healthy subjects. However, long duration follow-up studies using both objective and subjective sleep parameters to examine when sleep recovers after CABG surgery are needed and so this prospective study used both measures of sleep and had a control group in order to evaluate the sleep characteristics of patients in the early (preoperative) and late (postoperative) periods after $\mathrm{CABG}$ surgery.

\section{Methods}

Eighty-five alert patients, comprising 45 patients (23 males, 22 females) who underwent CABG surgery with cardiopulmonary bypass, and 40 healthy subjects ( 20 males 20 females) in nearly the same age range were evaluated. The study was approved by the institutional ethics committee. All participants gave their written informed consent and none had any complications related to the operation. None of them had any sleep disturbance or neurological disorders such as stroke or tremor affecting the non-dominant arm movement (because of the need to wear a wrist actigraph), anxiety, or peptic ulcers. None of the patients was taking either drug that could be related to sleep disorders or central nervous system depressants.

All subjects completed the Hamilton Anxiety Rating Scale and other anxiety measurements those with a score $>5$ were excluded from the study 15 All subjects were instructed to complete a standard sleep diary each morning during the period of actigraph use. The sleep instruments used in this study included subjective materials such as a 
Table 1 Demographic Findings and Sleep Parameters

\begin{tabular}{|c|c|c|c|c|c|}
\hline & \multicolumn{2}{|c|}{ Control group } & \multicolumn{2}{|c|}{ Study group (preoperative period) } & \multirow{2}{*}{$p$ value } \\
\hline & Female & Male & Female & Male & \\
\hline \multicolumn{6}{|l|}{ Demographic findings } \\
\hline Total no. of subjects & 20 & 20 & 19 & 19 & $0.551 *$ \\
\hline Age $>60$ years, $n$ & 11 & 11 & 10 & 10 & \\
\hline Age $<60$ years, $n$ & 9 & 9 & 9 & 9 & \\
\hline Age (years) & $\begin{array}{c}59.80 \pm 7.38 \\
(43.00-68.00)\end{array}$ & $\begin{array}{l}62.05 \pm 6.40 \\
(49.00-72.00)\end{array}$ & $\begin{array}{l}60.13 \pm 6.71 \\
(42.00-68.00)\end{array}$ & $\begin{array}{c}61.13 \pm 6.51 \\
(43.00-72.00)\end{array}$ & $0.332 *$ \\
\hline \multicolumn{6}{|l|}{ Subjective parameters } \\
\hline PSQI (points) & $\begin{array}{c}2.70 \pm 1.33 \\
(0.00-4.00)\end{array}$ & $\begin{array}{c}2.67 \pm 1.42 \\
(0.00-4.00)\end{array}$ & $\begin{array}{c}2.87 \pm 0.90 \\
(1.00-5.00)\end{array}$ & $\begin{array}{c}2.91 \pm 0.63 \\
(1.00-5.00)\end{array}$ & $0.412 *$ \\
\hline ESS (points) & $\begin{array}{c}2.00 \pm 1.21 \\
(0.00-6.00)\end{array}$ & $\begin{array}{c}2.04 \pm 1.11 \\
(0.00-6.00)\end{array}$ & $\begin{array}{c}2.05 \pm 0.90 \\
(0.00-6.00)\end{array}$ & $\begin{array}{c}2.29 \pm 0.16 \\
(0.00-6.00)\end{array}$ & $0.339 *$ \\
\hline \multicolumn{6}{|l|}{ Objective parameters } \\
\hline$M W T(\min )$ & $\begin{array}{c}18.00 \pm 1.07 \\
(17.00-20.00)\end{array}$ & $\begin{array}{l}17.60 \pm 1.00 \\
(14.00-20.00)\end{array}$ & $\begin{array}{l}17.90 \pm 1.32 \\
(14.00-20.00)\end{array}$ & $\begin{array}{c}18.39 \pm 1.06 \\
(14.00-20.00)\end{array}$ & $0.489 *$ \\
\hline$S L(\min )$ & $\begin{array}{l}16.00 \pm 7.11 \\
(10.00-31.00)\end{array}$ & $\begin{array}{l}17.00 \pm 7.43 \\
(10.00-32.00)\end{array}$ & $\begin{array}{l}15.83 \pm 8.33 \\
(9.00-30.00)\end{array}$ & $\begin{array}{l}16.13 \pm 7.45 \\
(9.00-30.00)\end{array}$ & $0.357 *$ \\
\hline$T S T$ (h/night) & $\begin{array}{c}7.18 \pm 0.56 \\
(6.39-8.45)\end{array}$ & $\begin{array}{c}7.09 \pm 0.61 \\
(5.59-8.00)\end{array}$ & $\begin{array}{l}7.16 \pm 0.51 \\
(6.00-8.05)\end{array}$ & $\begin{array}{l}7.11 \pm 0.32 \\
(6.25-8.06)\end{array}$ & $0.431 *$ \\
\hline Total activity score (n/night) & $\begin{array}{c}8,700 \pm 7,324 \\
(3,000-23,800)\end{array}$ & $\begin{array}{c}9,780 \pm 7,215 \\
(2,100-21,980)\end{array}$ & $\begin{array}{c}9,651 \pm 7,300 \\
(1,034-23,180)\end{array}$ & $\begin{array}{c}8,738 \pm 7,204 \\
(2,334-22,280)\end{array}$ & $0.481 *$ \\
\hline WASO (min) & $\begin{array}{l}14.30 \pm 2.00 \\
(6.00-61.00)\end{array}$ & $\begin{array}{l}15.00 \pm 2.01 \\
(5.00-62.00)\end{array}$ & $\begin{array}{l}14.44 \pm 2.01 \\
(5.00-60.00)\end{array}$ & $\begin{array}{l}14.10 \pm 2.00 \\
(6.00-60.00)\end{array}$ & $0.465 *$ \\
\hline$F I($ n/day $)$ & $\begin{array}{l}8.80 \pm 1.19 \\
(2.00-18.00)\end{array}$ & $\begin{array}{l}9.33 \pm 1.20 \\
(1.89-18.00)\end{array}$ & $\begin{array}{l}9.03 \pm 1.20 \\
(1.94-17.80)\end{array}$ & $\begin{array}{l}8.43 \pm 1.23 \\
(1.90-17.00)\end{array}$ & $0.421^{*}$ \\
\hline$S E(\%)$ & $\begin{array}{c}94.70 \pm 1.21 \\
(51.00-98.00)\end{array}$ & $\begin{array}{l}94.01 \pm 0.94 \\
(50.00-98.00)\end{array}$ & $\begin{array}{c}93.70 \pm 12.21 \\
(59.00-98.00)\end{array}$ & $\begin{array}{c}92.65 \pm 15.21 \\
(59.00-99.00)\end{array}$ & $0.398 *$ \\
\hline Daytime naps (n/day) & $\begin{array}{c}2.45 \pm 1.04 \\
(0-4)\end{array}$ & $\begin{array}{c}2.41 \pm 0.71 \\
(0-4)\end{array}$ & $\begin{array}{c}2.35 \pm 0.69 \\
(1-4)\end{array}$ & $\begin{array}{c}2.86 \pm 1.19 \\
(1-4)\end{array}$ & $0.477 *$ \\
\hline Total nap duration (min/day) & $\begin{array}{c}30.10 \pm 4.10 \\
(15.00-57.00)\end{array}$ & $\begin{array}{l}31.00 \pm 4.20 \\
(15.00-60.40)\end{array}$ & $\begin{array}{l}32.00 \pm 4.00 \\
(15.00-56.00)\end{array}$ & $\begin{array}{l}33.00 \pm 4.13 \\
(15.00-59.00)\end{array}$ & $0.456^{*}$ \\
\hline p value & \multicolumn{2}{|c|}{$0.319^{* *}$} & \multicolumn{2}{|c|}{$0.311 * *$} & \\
\hline
\end{tabular}

Data are mean, range unless otherwise stated. *Determined by 1-way analysis of variance. **Determined by Wilcoxon signed rank test. PSQI, Pittsburgh Sleep Quality Index; ESS, Epworth Sleepiness Scale; MWT, Maintenance of Wakefulness Test; SL, sleep latency; TST, total sleep time; WASO, wakefulness after sleep onset; FI, fragmentation index; SE, sleep efficiency.

standard sleep diary, the Pittsburgh Sleep Quality Index (PSQI) and the Epworth Sleepiness Scale (ESS) and objective parameters such as the Maintenance Wakefulness Test (MWT) and actigraphy.

Participation in this study was over a period of nearly 80 days, including preoperative measurement at least 3 days before surgery and for postoperative 3 periods: (1) consecutive 5-8-day period in the $1^{\text {st }}$ postoperative week, (2) consecutive 5-8-day period in the $1^{\text {st }}$ postoperative month and (3) consecutive 5-8-day period in the $2^{\text {nd }}$ postoperative month. Wrist actigraphs were not used during the operation or on the $1^{\text {st }}$ postoperative day. Control subjects wore the wrist actigraphs continuously for a 7-day period.

\section{Subjective Sleep Parameters}

A standard sleep diary was used to record bed times, sleep onset, frequency and duration of awakening during the sleep period, final awakening time, and nap times during the day. These data were used to assist in the scoring and interpretation of the actigraph records.

The PSQI is a subjective measurement of sleep quality and disturbances during the past month. All subjects answered the 19 questions, and results were assessed as "good sleep quality" for scores $\leq 5$ or as "bad" for scores $>5 ! 6$

The ESS was used to evaluate the general level of selfreported daytime sleepiness or the "average sleep propensity" during the preceding week. The total ESS score is 24 maximally, and results $\geq 10$ were assessed as indicating sleepiness! ${ }^{17}$

\section{Objective Sleep Parameters}

The MWT was performed by forcing the subjects remain awake in a silent and dim room for 20-min periods at 4 times, with a 2-h break after each period. Average wakefulness time was calculated by dividing the total sum of the length of the wakeful period that the patients were able to maintain by 4 . All subjects underwent the MWT from 13.00 to $21.00 \mathrm{~h}$ to evaluated drowsiness! ${ }^{15}$

The actigraphs (Actiwatch, AW64 ${ }^{\circledR}$, Mini-Mitter Co Inc, Bend, OR, USA) were used to measure duration of time in bed for the major (nocturnal) sleep period, TST during the major sleep period, nap time (sleep occurring outside the major sleep period), nocturnal frequency of awakenings, duration of awakenings, and SE [(nocturnal sleep time/time in bed) $\times 100$ ]. The actimeters are designed for long-term monitoring of gross motor activity in humans and have an accelerometer capable of sensing motion with a minimal resultant force of $0.01 \mathrm{G} !^{18}$ The actigraphs were attached to participants' non-dominant wrist for at least 3 days before surgery, then for the 3 postoperative study periods. Control group subjects wore the wrist actigraphs continuously over a 7-day period to evaluate sleep duration and continuity, as well as to obtain some information about daytime naps. All actimeters had a maximum frequency of $32 \mathrm{~Hz}$ and were calibrated prior to use and set to collect data at 30-s intervals. Device sensitivities were determined to indicate that motor activity $\geq 20$ indicated being awake. A minimum of $10 \mathrm{~min}$ without motor activity after pressing the marker was determined to be sleep onset ${ }^{18}$ Motor activity $<5$ was 
Table 2 Subjective and Objective Parameters of Sleep in the Gender Subgroups

\begin{tabular}{|c|c|c|c|c|c|c|c|c|}
\hline \multirow{2}{*}{ Parameters } & \multicolumn{2}{|c|}{ Preoperative period } & \multicolumn{2}{|c|}{ Postoperative $1^{\text {st }}$ week } & \multicolumn{2}{|c|}{ Postoperative $1^{s t}$ month } & \multicolumn{2}{|c|}{ Postoperative $2^{\text {nd }}$ month } \\
\hline & Female & Male & Female & Male & Female & Male & Female & Male \\
\hline \multicolumn{9}{|l|}{ Subjective } \\
\hline PSQI (points) & $\begin{array}{c}2.87 \pm 0.90 \\
(1.00-5.00)\end{array}$ & $\begin{array}{c}2.91 \pm 0.63 \\
(1.00-5.00)\end{array}$ & $\begin{array}{l}5.60 \pm 0.91 * \\
(4.00-7.00)\end{array}$ & $\begin{array}{c}6.05 \pm 0.74 * \\
(4.00-8.00)\end{array}$ & $\begin{array}{c}2.90 \pm 0.80 \\
(1.00-5.00)\end{array}$ & $\begin{array}{c}3.09 \pm 0.17 \\
(1.00-6.00)\end{array}$ & $\begin{array}{c}2.60 \pm 0.83 \\
(0.00-4.00)\end{array}$ & $\begin{array}{c}2.85 \pm 0.82 \\
(0.00-5.00)\end{array}$ \\
\hline ESS (points) & $\begin{array}{c}2.05 \pm 0.90 \\
(0.00-6.00)\end{array}$ & $\begin{array}{c}2.29 \pm 0.16 \\
(0.00-6.00)\end{array}$ & $\begin{array}{c}6.27 \pm 1.05^{*} \\
(4.00-9.00)\end{array}$ & $\begin{array}{l}6.36 \pm 1.08^{*} \\
(3.00-8.00)\end{array}$ & $\begin{array}{c}2.23 \pm 1.01 \\
(0.00-6.00)\end{array}$ & $\begin{array}{c}2.26 \pm 1.08 \\
(0.00-7.00)\end{array}$ & $\begin{array}{c}2.01 \pm 1.00 \\
(0.00-6.00)\end{array}$ & $\begin{array}{c}2.10 \pm 0.81 \\
(0.00-6.00)\end{array}$ \\
\hline \multicolumn{9}{|l|}{ Objective } \\
\hline$M W T$ (min) & $\begin{array}{l}17.90 \pm 1.32 \\
(14.00-20.00)\end{array}$ & $\begin{array}{l}18.39 \pm 1.06 \\
(14.00-20.00)\end{array}$ & $\begin{array}{c}16.23 \pm 1.04 * \\
(14.00-18.00)\end{array}$ & $\begin{array}{c}16.40 \pm 1.11^{*} \\
(15.00-19.00)\end{array}$ & $\begin{array}{l}17.02 \pm 1.01 \\
(14.00-19.00)\end{array}$ & $\begin{array}{l}17.20 \pm 1.01 \\
(14.00-19.00)\end{array}$ & $\begin{array}{l}18.20 \pm 1.00 \\
(17.00-20.00)\end{array}$ & $\begin{array}{l}18.24 \pm 1.01 \\
(17.00-20.00)\end{array}$ \\
\hline$S L($ & $\begin{array}{l}15.83 \pm 8.33 \\
(9.00-30.00)\end{array}$ & $\begin{array}{l}16.13 \pm 7.45 \\
(9.00-30.00)\end{array}$ & $\begin{array}{c}23.00 \pm 6.04 * \\
(15.00-35.00)\end{array}$ & $\begin{array}{c}23.19 \pm 6.15^{*} \\
(11.00-40.00)\end{array}$ & $\begin{array}{c}17.00 \pm 7.24 \\
(10.00-33.00)\end{array}$ & $\begin{array}{l}17.39 \pm 6.55 \\
(10.00-34.00)\end{array}$ & $\begin{array}{l}16.00 \pm 7.00 \\
(10.00-30.00)\end{array}$ & $\begin{array}{l}16.02 \pm 7.13 \\
(10.00-30.00)\end{array}$ \\
\hline$T S T$ (h/night) & $\begin{array}{l}7.16 \pm 0.51 \\
(6.00-8.05)\end{array}$ & $\begin{array}{l}7.11 \pm 0.32 \\
(6.25-8.06)\end{array}$ & $\begin{array}{l}6.00 \pm 0.80^{* *} \\
(4.25-7.42)\end{array}$ & $\begin{array}{l}6.02 \pm 0.78^{* *} \\
(4.20-8.20)\end{array}$ & $\begin{array}{c}7.03 \pm 0.88 \\
(6.00-7.40)\end{array}$ & $\begin{array}{c}7.06 \pm 0.83 \\
(6.00-8.10)\end{array}$ & $\begin{array}{c}7.10 \pm 0.32 \\
(5.58-8.25)\end{array}$ & $\begin{array}{c}7.16 \pm 0.52 \\
(5.59-8.10)\end{array}$ \\
\hline $\begin{array}{c}\text { Total activity score } \\
(n / \text { night })\end{array}$ & $\begin{array}{c}9,651 \pm 7,300 \\
(1,034-23,180)\end{array}$ & $\begin{array}{c}8,738 \pm 7,204 \\
(2,334-22,280)\end{array}$ & $\begin{array}{r}5,671 \pm 6,811^{*} \\
(1,243-18,591)\end{array}$ & $\begin{array}{c}5,880 \pm 6,980^{*} \\
(2,421-17,571)\end{array}$ & $\begin{array}{c}8,279 \pm 7,800 \\
(2,243-23,000)\end{array}$ & $\begin{array}{c}8,280 \pm 7,200 \\
(3,421-23,500)\end{array}$ & $\begin{array}{c}8,800 \pm 7,324 \\
(3,000-23,000)\end{array}$ & $\begin{array}{l}9,180 \pm 7,015 \\
(2,900-24,980)\end{array}$ \\
\hline WASO (min) & $\begin{array}{l}14.44 \pm 2.01 \\
(5.00-60.00)\end{array}$ & $\begin{array}{l}14.10 \pm 2.00 \\
(6.00-60.00)\end{array}$ & $\begin{array}{c}37.14 \pm 2.21^{*} \\
(25.00-70.00)\end{array}$ & $\begin{array}{c}36.17 \pm 2.18^{*} \\
(28.00-69.00)\end{array}$ & $\begin{array}{l}15.14 \pm 2.61 \\
(8.00-60.00)\end{array}$ & $\begin{array}{l}16.17 \pm 2.35 \\
(7.00-61.00)\end{array}$ & $\begin{array}{l}14.10 \pm 2.07 \\
(6.00-55.00)\end{array}$ & $\begin{array}{l}14.20 \pm 2.00 \\
(5.00-57.00)\end{array}$ \\
\hline$F I($ n/day $)$ & $\begin{array}{l}9.03 \pm 1.20 \\
(1.94-17.80)\end{array}$ & $\begin{array}{l}8.43 \pm 1.23 \\
(1.90-17.00)\end{array}$ & $\begin{array}{l}15.60 \pm 2.10^{*} \\
(6.90-19.50)\end{array}$ & $\begin{array}{l}16.10 \pm 2.00 * \\
(7.42-19.90)\end{array}$ & $\begin{array}{l}9.54 \pm 2.30 \\
(1.90-19.50)\end{array}$ & $\begin{array}{l}9.70 \pm 2.01 \\
(2.42-19.90)\end{array}$ & $\begin{array}{l}8.80 \pm 1.19 \\
(1.00-16.00)\end{array}$ & $\begin{array}{l}9.33 \pm 1.20 \\
(1.89-17.00)\end{array}$ \\
\hline$S E(\%)$ & $\begin{array}{c}93.70 \pm 12.21 \\
(59.00-98.00)\end{array}$ & $\begin{array}{c}92.65 \pm 15.21 \\
(59.00-99.00)\end{array}$ & $\begin{array}{c}67.80 \pm 13.72 * \\
(45.40-88.20)\end{array}$ & $\begin{array}{c}66.55 \pm 11.00^{*} \\
(45.00-80.00)\end{array}$ & $\begin{array}{c}92.20 \pm 14.92 \\
(65.40-99.20)\end{array}$ & $\begin{array}{c}92.21 \pm 11.17 \\
(66.00-99.00)\end{array}$ & $\begin{array}{c}94.10 \pm 1.21 \\
(71.00-98.00)\end{array}$ & $\begin{array}{c}94.01 \pm 0.94 \\
(70.00-98.00)\end{array}$ \\
\hline $\begin{array}{c}\text { Daytime naps } \\
\text { (n/day) }\end{array}$ & $\begin{array}{c}2.35 \pm 0.69 \\
(1-4)\end{array}$ & $\begin{array}{c}2.86 \pm 1.19 \\
(1-4)\end{array}$ & $\begin{array}{c}5.50 \pm 1.78^{*} \\
(2-11)\end{array}$ & $\begin{array}{c}5.81 \pm 1.23 * \\
(2-11)\end{array}$ & $\begin{array}{c}2.65 \pm 1.80 \\
(1-5)\end{array}$ & $\begin{array}{c}2.70 \pm 1.20 \\
(1-5)\end{array}$ & $\begin{array}{c}2.15 \pm 1.04 \\
(0-4)\end{array}$ & $\begin{array}{c}2.11 \pm 0.71 \\
(0-4)\end{array}$ \\
\hline $\begin{array}{l}\text { Total nap duration } \\
\quad(\text { min/day })\end{array}$ & $\begin{array}{c}32.00 \pm 4.00 \\
(15.00-56.00)\end{array}$ & $\begin{array}{c}33.00 \pm 4.13 \\
(15.00-59.00)\end{array}$ & $\begin{array}{l}98.70 \pm 8.53 * \\
(54.11-143.00)\end{array}$ & $\begin{array}{l}101.02 \pm 9.00 * \\
(54.91-151.07)\end{array}$ & $\begin{array}{l}34.00 \pm 4.23 \\
(14.11-60.00)\end{array}$ & $\begin{array}{c}33.80 \pm 4.32 \\
(14.91-59.07)\end{array}$ & $\begin{array}{c}30.10 \pm 4.10 \\
(15.00-51.00)\end{array}$ & $\begin{array}{c}31.00 \pm 4.20 \\
(15.00-52.40)\end{array}$ \\
\hline
\end{tabular}

*One-way analysis of variance was used to compare the values of the periods. ${ }^{*} p<0.001, * * p<0.001$.

Abbreviations see in Table 1.

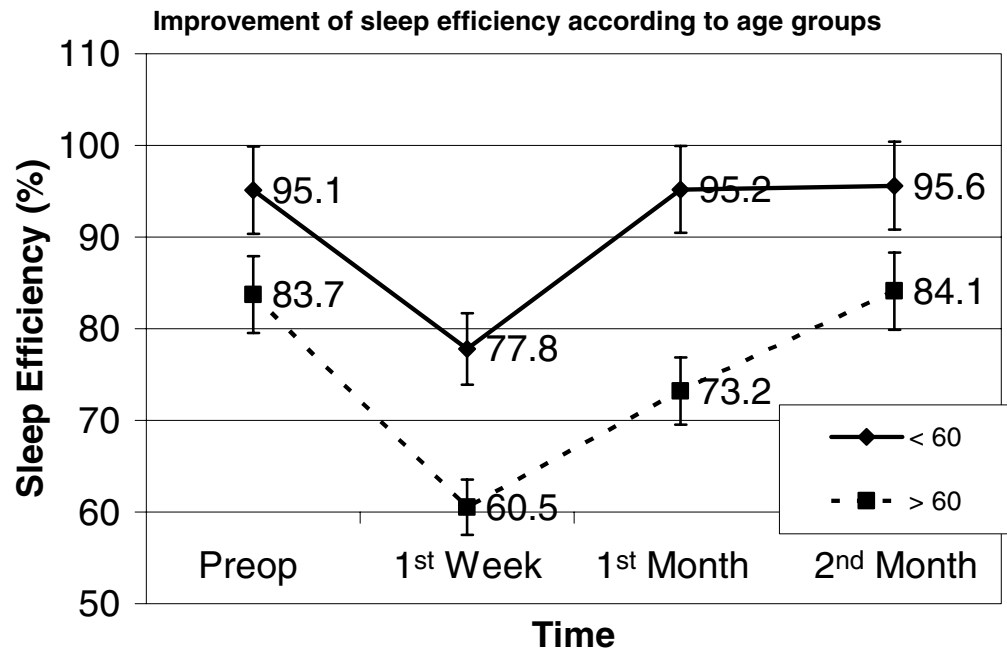

Fig 1. Improvement in sleep efficiency according to age group.

assessed as occurring in a sleep period in the analysis of napping. Nap times were determined to be a minimum of $15 \mathrm{~min}$, as in the study by Brooks 19 The primary sleep period was recognized based on the times when contributors depressed the event markers to indicate "lights out" and "lights on." TST was calculated by removing any period of awakening from the TST during the night.

Daily sleep and daytime activity variables, sleep latency (SL) (time from lights out to sleep onset), percentage of wakefulness after sleep onset (WASO), and total activity score (TAS) parameters were determined. Computer programs were used to determine the levels of activity/inactivity, sleepiness/wakefulness parameters such as duration of time in bed for the nocturnal sleep period and TST during the major sleep period, and percentage of time spent asleep. Total awake time, percentage of time spent awake, number/frequency of awakenings, duration of awakenings, $\mathrm{SE}$, and nap times were also calculated.

Statistical Analysis

The data were entered into the SPSS version 10.0 program (Chicago, IL, USA). Wilcoxon signed rank test, and 1 -way analysis of variance were used for statistical evaluation. A p-value $<0.05$ was considered significant.

\section{Results}

We started with 45 surgical subjects, but 4 males and 3 females could not participate in the $1^{\text {st }}$ or $2^{\text {nd }}$ month, so 38 cardiac surgery patients and 40 healthy control subjects completed the study. In the study group, the mean age was 61.1 years for male patients and 60.1 years for females. In 
the control group, the mean age was 62.0 and 59.8 years respectively. There were no statistically significant age or sex differences between the groups (Table 1).

None of the scores for subjective and objective sleep parameters were statistically different the between study and control groups in the preoperative period (Table 1). All patients had an uncomplicated recovery from surgery. Descriptive statistics obtained for the activity variables are also shown in Table 1.

In the surgical group, the PSQI and ESS scores in the $1^{\text {st }}$ postoperative week were significantly higher than the preoperative values. MWT, TST, TAS and SE scores for the same period were significantly shorter, but SL, WASO fragmentation index, daytime napping episodes and total nap duration in the same period were significantly higher than the preoperative values (Table 2). None of the sleep parameters for the $1^{\text {st }}$ and $2^{\text {nd }}$ postoperative month were significantly different from the preoperative sleep parameters. Subjective and objective sleep parameters of the $2^{\text {nd }}$ postoperative month were better than those for the preoperative period but the differences were not statistically significant (Table 2).

We also separated the patients according to age greater or lower than 60 years in order to examine the relationship between age and sleep parameters. Subjective and objective sleep characteristics returned to normal values during the $1^{\text {st }}$ month in the younger patients but by the end of the $2^{\text {nd }}$ month in the elderly (Fig 1).

\section{Discussion}

Sleep disturbance, poor sleep quality, and sleep continuity (difficulty falling asleep, restless sleep with frequent nocturnal awakenings, and early morning awakenings) are common among patients during recovery after cardiac surgical procedures and may have some important effects on morbidity, mortality, and quality of life ${ }^{2-6,20}$ Nearly $39-69 \%$ report that sleep disturbances after CABG operation may persist for weeks or months 2,3 Many studies have been performed in order to examine when the disturbed sleep returns to normal. In one study using daily questionnaires, sleeplessness complaint were maximal on the $1^{\text {st }}$ postoperative day and declined after the $3^{\text {rd }}$ postoperative day and were finally described as lower than the preoperative level on the $6^{\text {th }}$ postoperative day after CABG surgery? SE was reported as $45 \%$ on the $2^{\text {nd }}$ postoperative day and increased to nearly $60 \%$ by the $5^{\text {th }}$ postoperative day after CABG surgery ${ }^{3}$ On the other hand, in some reports $68 \%$ of patients who underwent CABG surgery complained of sleeplessness ${ }^{4}$ and Magni et al reported that sleep disturbance persisted for nearly 1 year after heart surgery? ${ }^{2}$ Although sleep disturbances can persist for weeks to months after cardiac surgery, there is some evidence that they continue to improve over the course of recovery. A group of female patients who had undergone CABG showed significant increments in nighttime sleep, the percentage of total daily sleep occurring at night, and diminished daytime sleep, the number of nocturnal awakenings (measured with wrist actigraphy), and improvements in self-reported sleep quality from hospital discharge through the $6^{\text {th }}$ postoperative month ${ }^{22}$ If the studies of self-reported diaries and objectively measured sleep parameters after cardiac surgery were considered together, it would suggest that sleep is severely disturbed during the early postoperative period and improves progressively during the $1^{\text {st }}$ postoperative week and over the weeks and months after surgery. Lukkarinen found that sleep improved at 6 months, ${ }^{23}$ whereas Chocron et al ${ }^{11}$ found it was during the $1^{\text {st }}$ year after surgery relative to preoperative sleep.

Follow-up duration in the studies that used objective parameters have been inadequate for obtaining any useful information and some long-term studies have not used objective sleep parameters. Therefore, we used both subjective and objective sleep parameters in a long-term study that included healthy subjects as a control group. We detected that disturbed sleep after surgery improved at the end of the $1^{\text {st }}$ postoperative month.

All subjects were separated according to age and gender subgroups, unlike in previous studies. SL and WASO times in the older group were longer than those of the younger group, and total sleep duration and SE were diminished in this subgroup compared with the younger patients. These findings are consistent with the literature 24,25

Sleep characteristics returned to normal values at the end of the $1^{\text {st }}$ month in the younger subgroup but by the end of the $2^{\text {nd }}$ month in the older subgroup. These normalization periods have extended up to the $3^{\text {rd }}$ postoperative month in some studies that used subjective parameters $!^{10}$ Older age may be a risk factor for sleep disturbance after cardiac surgery. Sleep disturbances may occur more easily and return to normal later in older patients. We suspect that improvement of sleep characteristics requires a longer period in the older patients because a longer time is necessary for cerebral autoregulation.

Sleep latencies and WASO times were shorter in women than in men. TSTs and sleep efficiencies were higher in women. Our findings are consistent with the report of JeanLouis et al ${ }^{26}$ but not that of Reyner who used only subjective methods ${ }^{27}$ Sleep constitution has been determined actigraphically as better in women in both the preoperative and postoperative periods $!^{3}$ In contrast with this finding some authors report that sleep constitution improved later in women than in men after $\mathrm{CABG}^{28}$ In the present study we found that sleep characteristics improved in the early postoperative period in women and we consider that our findings are more reliable because we also evaluated healthy control subjects and used both subjective and objective parameters.

We determined that sleep disturbances after CABG surgery have improved at the end of the $2^{\text {nd }}$ postoperative month. Sleep characteristics in younger or female subgroups improved earlier than related subjects. Sleep characteristics were disturbed more evidently in the older subgroup and their improvement took longer than in the others. Cerebral autoregulation may be more easily disturbed in older subjects and may also improved later.

We propose that the essential cause of the sleep disturbances after CABG surgery using cardiopulmonary bypass is temporary deterioration of the circulation of the centers of the brain stem and hypothalamus that control sleep and awakening! Improvement in the circulation of these centers in the months after operation regains the control of sleep and thus disturbances disappear.

\section{Study Limitations}

The effects of anesthesia and circadian rhythm changes on sleep must be eliminated in order to clarify the exact mechanism of sleep disturbance, because the effects of anesthesia and circadian rhythm disturbances on sleep after major surgery have been reported 29 Further study is under- 
way to confirm these findings. There are also findings that suggest the role of cardiopulmonary bypass on neurocognitive impairment based on off-pump cardiac surgery $3^{30}$ There is need for further research in order to obtain useful information about the importance whether anesthesia or cardiopulmonary bypass has the most effect on the sleep disturbance after major surgery. In addition to these conclusions, actigraphic sleep examinations give very important knowledge about sleep continuity but are less informative about the sleep constitution. Further studies that use of polysomnography with our study protocols may be beneficial in order to understand sleep disturbances after CABG.

\section{References}

1. Yilmaz H, Iskesen I. Objective and subjective characteristics of sleep after coronary artery bypass graft surgery in the early period: A prospective study with healthy subjects. Heart Surg Forum 2007; 10: $16-20$.

2. Tack BB, Gillis CL. Nurse-monitored cardiac recovery: A description of the first 8 weeks. Heart Lung 1990; 19: 491-499.

3. King KB, Parinello KA. Patient perceptions of recovery from coronary artery bypass grafting after discharge from the hospital. Heart Lung 1988; 17: 708-715.

4. Schaefer KM, Swavely D, Rothenberger C, Hess S, Williston D. Sleep disturbances post coronary artery bypass surgery. Prog Cardiovasc Nurs 1996; 11: 5-14.

5. Redeker NS, Hedges C. Sleep during hospitalization and recovery after cardiac surgery. J Cardiovasc Nurs 2002; 17: 56-68.

6. Redeker NS, Ruggiero JS, Hedges C. Sleep is related to physical function and emotional well-being after cardiac surgery. Nurs Res 2004; 53: $154-162$.

7. Edell-Gustaffson UM, Hetta JE. Anxiety, depression, and sleep in male patients undergoing coronary artery bypass surgery. Scand $J$ Card Sci 1999; 13: 137-143.

8. Hunt JO, Hendrata MV, Myles P. Quality of life 12 months after coronary artery bypass graft surgery. Heart Lung 2000; 29: $401-$ 411.

9. Knapp-Spooner C, Yarcheski A. Sleep patterns and stress in patients having coronary bypass. Heart Lung 1992; 21: 342-349.

10. Chocron S, Etievent JP, Viel JF, Dussaucy A, Clement F, Alwan K, et al. Prospective study of quality of life before and after open heart operations. 1996; 61: 153-157.

11. Chocron S, Tatou E, Schjoth B, Naja G, Clement F, Viel JF, et al. Perceived health status in patients over 70 before and after open-heart operations. Age Ageing 2000; 29: 329-334.

12. Simpson T, Lee E. Individual factors that influence sleep after car- diac surgery. Am J Crit Care 1996; 5: 182-189.

13. Redeker NS, Wykpisz E. Gender differences in sleep and activityrest after coronary bypass. Sleep 1998; 21: 211.

14. Gustaffson UM, Hetta J, Aren CB, Hamrin EKF. Measurement of sleep and quality of life before and after coronary artery bypass grafting. Int J Nurs Pract 1997; 3: 239-246.

15. Hofer S, Doering S, Rumpold G, Oldridge N, Benzer W. Determinants of health-related quality of life in patients with coronary artery disease. Eur J Cardiovasc Prev Rehab 2006; 13: 398-406.

16. Hedges C. Sleep, memory, and learning in off-pump coronary artery bypass patients. Res Nurs Health 2005; 28: 462-473.

17. Hedner J, Caidahl K, Sjoland H, Karlsson T, Herlitz J. Sleep habits and their association with mortality during 5-year follow-up after coronary artery bypass surgery. Acta Cardiol 2002; 57: 341 -348.

18. Sadeh A, Hauri PJ, Kripke DF, Lavie P. The role of actigraphy in the evaluation of sleep disorders. Sleep 1995; 18: 288-302.

19. Brooks A, Lack L. A brief afternoon nap following nocturnal sleep restriction: Which nap duration is most recuperative? Sleep 2006; 29: $831-840$.

20. Simpson T, Lee E. Individual factors that influence sleep after cardiac surgery. Am J Crit Care 1996; 5: 182-189.

21. Magni G, Unger HP, Valfre C, Polesel E, Cesari F, Rizzardo R. Psychosocial outcome one year after heart surgery: A prospective study. Arch Intern Med 1987; 147: 173-177.

22. Redeker NS, Mason DJ, Wykpisz E, Glica B. Sleep patterns in women after coronary artery bypass surgery. Appl Nurs Res 1996; 9: $115-122$.

23. Lukkarinen H. Quality of life in coronary artery disease. Nurs Res 1998; 47: 337-343.

24. Webb W, Campbell S. Awakenings and return to sleep in an older population. Sleep 1980; 3: 41-46.

25. Vitiello MV, Moe KE, Larssen LH, Prinz PN. Age-related sleep changes: Relationships of objective and subjective measures of sleep in healthy older men and women. Sleep Res 1997; 26: 220.

26. Jean-Louis G, von Gizycki H, Zizi F, Fookson J, Spielman A, Nunes $\mathrm{J}$, et al. Determination of sleep and wakefulness with the actigraph data analysis software (ADAS). Sleep 1996; 19: 739-743.

27. Reyner A, Horne JA. Gender- and age-related differences in sleep determined by home- recorded sleep logs and actimetry from 400 adults. Sleep 1995; 18: 127-134.

28. Kos-Munson BA, Alexander LD, Hinthorn PA, Gallagher EL, Goetz CM. Psychosocial predictors of optimal rehabilitation post-coronary artery bypass surgery. Sch Inq Nurs Pract 1988; 2: 171-199.

29. Karkela J, Vakkuri O, Kaukinen S, Huang WO, Pasanen M. The influence of anaesthesia and surgery on the circadian rhythm of melatonin. Acta Anaesthesiol Scand 2002; 46: 30-36.

30. Zamvar V, Williams D, Hall J, Payne N, Cann C, Young K, et al. Assessment of neurocognitive impairment after off-pump and onpump techniques for coronary artery bypass graft surgery: Prospective randomised controlled trial. BMJ 2002; 325: 1268. 